N4 SCHOOL OF MEDICINE DEPARTMENT OF RADIOLOGY

\title{
What's the story morning glory? A review of morning glory disc anomaly and associated findings.
}

\author{
Justin Marshall DO, Jon Hallstrom MD, Jacob Ormsby MD, Gamaliel Lorenzo MD, Marc Mabray MD
}

\begin{tabular}{l}
\multicolumn{1}{c|}{ Disclosures } \\
\hline No Disclosures. \\
\hline \multicolumn{1}{c|}{ Purpose } \\
\hline $\begin{array}{l}\text { To familiarize the participant with morning } \\
\text { glory disc anomaly (MGDA), the imaging } \\
\text { appearance, and associated imaging findings } \\
\text { to look for. }\end{array}$ \\
\hline
\end{tabular}

\section{Approach/Methods}

Review of MGDA including funduscopic findings, imaging appearance, and associated malformations.

\section{Findings/Discussion}

MGDA is a congenital malformation with characteristic findings on fundoscopic exam including a funnel-shaped excavation into the optic disc/optic nerve with surrounding peripapillary chorioretinal pigmentary changes, abnormal peripherally emanating vessels, and a central glial tuft. This unusual funduscopic appearance was likened to that of the morning glory flower, and so named.

While the diagnosis of MGDA is often made clinically, imaging features can be helpful in unusual clinical presentations as well as in patients with limited direct funduscopic visualization, such as those with persistent hyperplastic primary vitreous.

Typical MR image findings include excavation of the optic nerve head with elevation of the adjacent retina resulting in a so called "funnel-shape" morphology, abnormal tissue and signal of the intraorbital segment of the optic nerve, and a discontinuous uveoscleral coat.

MGDA has been associated with a number of intracranial abnormities, many of which are readily identifiable by cross sectional imaging.

Associated vascular abnormities include absence or hypoplasia of intracranial arteries and in some cases progressive Moyamoya vasculopathy.

A range of associated midline facial and cranial malformations can be seen including cephaloceles, ocular abnormalities such as persistent hyperplastic primary vitreous, congenital cataracts, nanophthalmos, retinal detachment, atrophy of the optic nerve and chiasm, and optic nerve glioma.

There is some suggestion that MGDA may be found within PHACE Syndrome; however, MGDA is less commonly familial or syndrome related than coloboma.
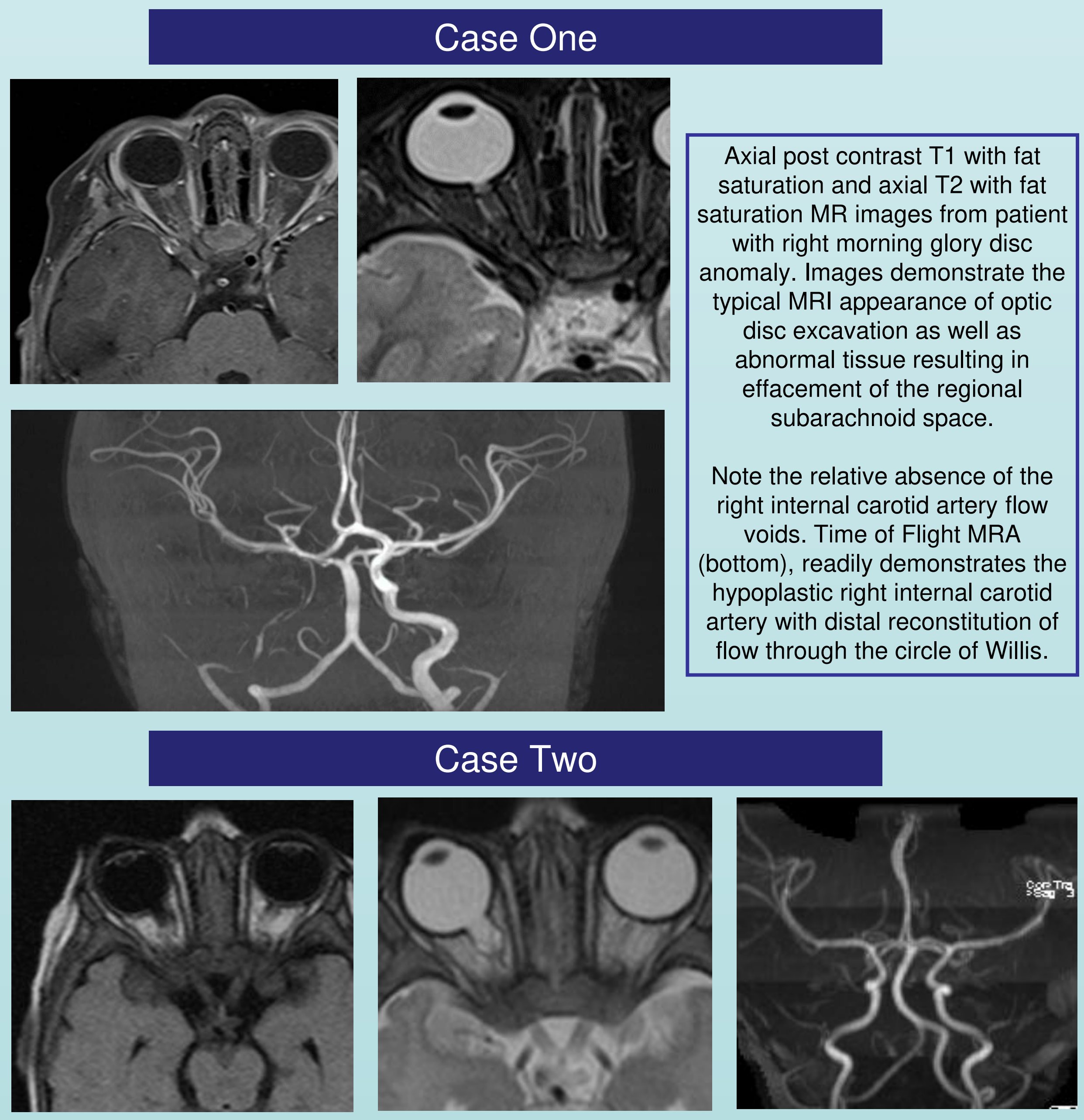

Axial T1 and T2 with fat saturation MR images taken from another patient with morning glory disc anomaly demonstrate a large excavation of the right optic disc/nerve. In comparison to case one, 3D MRA reveals that intracranial vasculature is preserved.

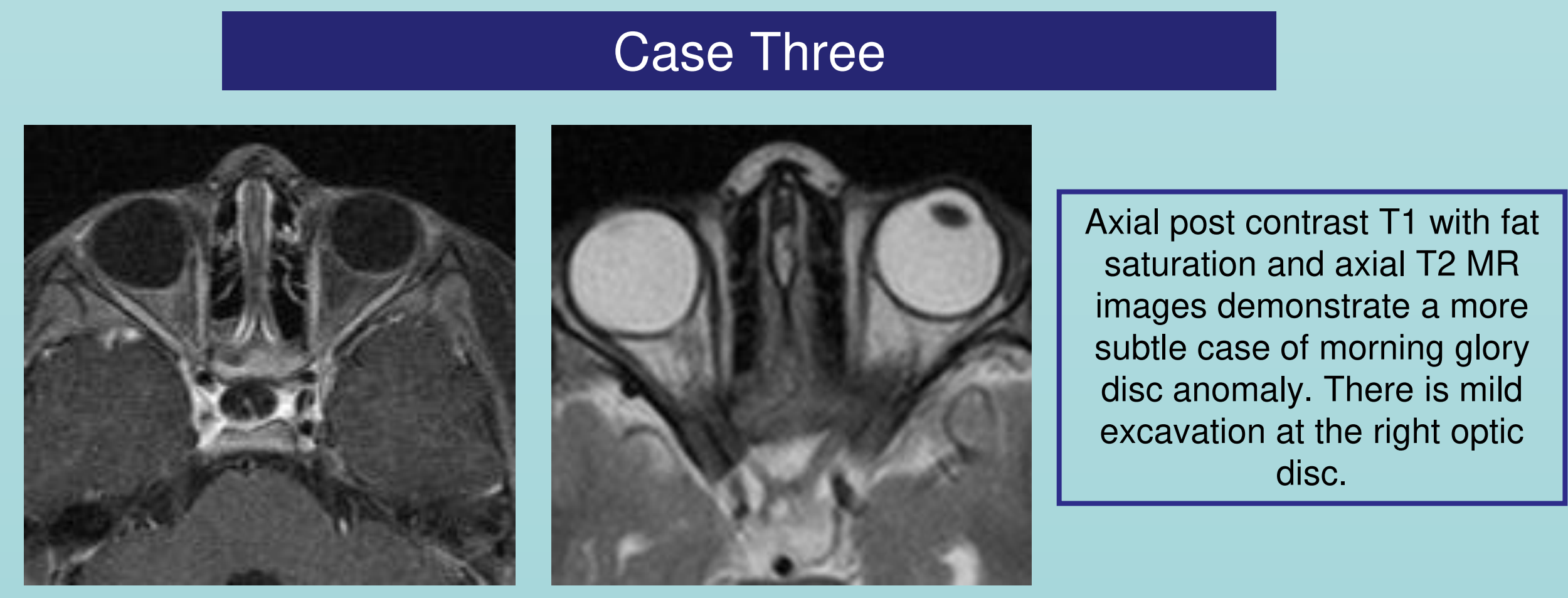

\section{Summary/Conclusion}

Morning glory disc anomaly is a congenital malformation centered at the optic disc/nerve with a specific appearance on funduscopic exam and

corresponding imaging findings. Once diagnosed a search should be made for a number of associated midline facial and intracranial vascular malformations.

Neuroradiologists and trainees should be familiar with this entity and associated malformations to look for on MRI/MRA.
References

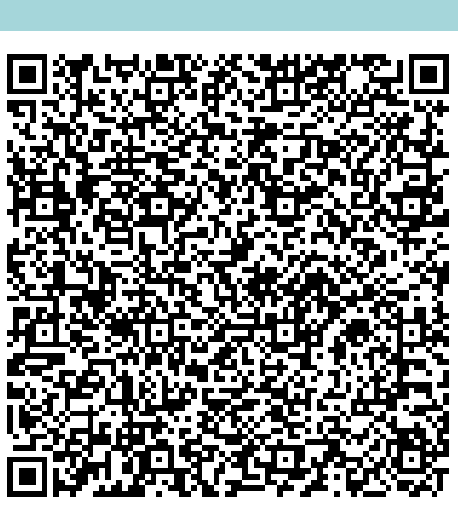

